\title{
Epistemic management in mathematics classroom interactions: Student claims of not knowing or not understanding
} Jenni Ingram, University of Oxford, UK.

\begin{abstract}
An important role of classroom interaction is the processes involved in knowing or coming to know. Following a conversation analytical approach, this study investigates how students' claims of not knowing, not remembering or not understanding are handled by mathematics teachers in whole class interactions. The study draws on video recordings of 42 mathematics lessons from 8 secondary schools in England. It is argued that claims of not knowing and claims of not remembering perform different social actions and are consequently treated differently by teachers. Claims of not knowing can challenge the assumption that knowledge can be taken-as-shared in a way that claims of not remembering do not. This contributes to the research field of mathematics classroom interaction as it nuances the epistemic management within these interactions and how this can contribute to the norms around the negotiation of meaning.
\end{abstract}

Keywords: classroom interaction; claims of insufficient knowledge; epistemic management; conversation analysis.

\section{Introduction}

One central concern in classroom interaction is the negotiation of meaning and the processes of knowing or coming to know. Classroom interactions are often dominated by teachers' questions and students' answers to these questions. There has been a great deal of research into the nature and content of classroom interaction that has revealed some common patterns, some of which may be prevalent in only a few classrooms (e.g. collective argumentation (Forman, Larreamendy-Joerns, Stein, \& Brown, 1998)), others of which occur in almost all classrooms (e.g. the IRE pattern discussed below). These patterns of interaction can become 'normative' in that they can underlie what it means to do school mathematics (Cobb, Wood, Yackel, \& McNeal, 1992). This paper considers the social norms or patterns of interaction around student claims of epistemological disalignment including claims of not knowing such as 'I don't know', as well as broader claims such as 'I don't understand', and the consequences these have on the management of epistemic concerns in the teaching and learning of mathematics. Using ethnomethodological conversation analysis (CA), a micro analytic approach is taken which focuses on the dynamic interactions between teachers and students. Classroom interaction is complex and the relationship between the social and the mathematical in interaction requires further research. CA research within mathematics education can been seen as adding further precision and understanding to analyses of mathematics classroom interactions (Emanuelsson \& Sahlström, 2008).

This paper begins with a summary of the most relevant research into patterns of interaction within the mathematics classroom, including work on norms as well as the IRE sequence. The theoretical and methodological approach is then outlined, including recent research on epistemic management using this approach from contexts other than classrooms. After the methods used to collect and analyse the data considered in this paper are described, the sequences of interaction where students have made claims of not remembering, not knowing and not understanding are considered in turn. The consequences of the different treatments of each of these claims is explored in terms of the epistemic access, rights, and responsibilities of students and teachers. 


\section{Background}

There has been considerable research on the social (co-)construction of knowledge and what it means to know within the mathematics classroom. Students' and teachers' knowing is made visible through their interactions as well as how it varies, develops and is negotiated in these interactions. Some of the most common theoretical perspectives emphasise the social and cultural nature of knowledge, including situated cognition and those building on the work of Vygotsky (e.g. Daniels, 2016; Vygotsky, 1978). These perspectives emphasise the social context of knowledge: what we know is shaped by our social context. Linguistic research within mathematics education has largely focused on how knowledge is shaped by language (e.g. Moschkovich, 2015), and in particular how specific mathematical terms affect what is understood and the meanings constructed (e.g. Rønning \& Strømskag, 2017). Wilkinson (2018) emphasises the need for teachers to know and use their knowing of the "communication challenges inherent to mathematics learning" (p. 167). However, more research is needed into the process through which epistemic concerns such as knowing and understanding are managed socially in and through interaction.

Research into the interactional management of claims of epistemological disalignment, in particular claims of not knowing such as 'I don't know', is limited (Sert \& Walsh, 2013), particularly within pedagogic interactions. There has been some research focused on how correct and appropriate as well as incorrect answers to teachers' questions are handled using a conversation analytic approach (e.g. Ingram, Pitt, \& Baldry, 2015; Lee, 2007). Earlier research into students' claims of not knowing using other perspectives has treated them as a type of hedge which avoids giving an incorrect response (Rowland, 1995). For example, Reis and Barwell (2012) examine an interaction where a student makes a claim of not remembering ('I forgot') in order to demonstrate how these claims are constructed by and consequential to the interactional context in which they arose. However, Reis and Barwell focus on the consequence of this for teachers' assessments of students rather than the interactional treatment of this claim, or any patterns in how claims like this are treated in pedagogic interactions.

A distinction can also be made between knowledge and knowing. Knowledge is often treated as something that we have or do not have. In the sequential context of a teacher asking a question that requires a student to demonstrate that they have the knowledge needed to answer, knowledge is also treated interactionally as something that students have or do not have. In contrast, interactions where students are negotiating meaning and building upon or contrasting with each other's ideas, knowing is treated as a continuing process that develops through this negotiation (Mason \& Spence, 1999). The relationship between knowing and understanding can also be problematic (Pirie \& Kieren, 1994; Sierpinska, 1994). From an interactionist perspective, what counts as knowledge, knowing or understanding depends upon how the participants themselves treat these epistemic issues in their interactions.

\subsection{Norms}

The idea of norms is widely considered from a range of theoretical perspectives in mathematics education research, and can also be referred to as practices or activities (e.g. Moschkovich, 2015), hidden regularities (Wood, Cobb, \& Yackel, 1993), or patterns of interaction. Classroom norms are intertwined with individual beliefs (Yackel \& Rasmussen, 2002) with Ju and Kwon (2007, p. 268) arguing that beliefs about what it means to learn or do mathematics can be considered as 'an individual's understandings of the normative expectations shared by a class'. Consequently, the classroom norms around what it means to 
do mathematics influence the development of students' mathematical beliefs. Furthermore, implicit norms have been shown to be an obstacle for students with low socio-economic status' participation in classroom interactions (Vogler, Prediger, Quasthoff, \& Heller, 2018), and that norms within a classroom can vary depending upon the language proficiency of multilingual students (Planas \& Gorgorió, 2004). Ryan and Parra (2019) argue that by making implicit norms and practices explicit can enable teachers to reflect on them and change them. In this paper the focus is on making explicit the specific type of norms that involve patterns of interactions and that relate to claims of epistemological disalignment.

Much of the research building upon the idea of norms and sociomathematical norms (Yackel \& Cobb, 1996) has taken a sociocultural perspective. Here, norms are social and cultural and play a central role in shaping classroom practice (Xu \& Clarke, 2013). Norms shape and give meaning to the actions of teachers and students in mathematics classrooms (Hofmann \& Ruthven, 2018). They are often taken for granted and enable the smooth interaction between teachers and students in classrooms. Classroom norms may be explicitly stated, or even consciously developed by teachers, but they may also be implicitly enacted and taken-forgranted. Norms can be considered at different levels ranging from the idea of cultural norms that pervade the teaching and learning of mathematics in particular countries, to the level of the particular mathematics classroom or even lesson or activity within a mathematics classroom, with ethnomethodological approaches focusing on the latter. Yackel and Cobb (1996, p. 178) define norms as 'regularities in communal or collective classroom activity which are considered to be jointly established by the teacher and students as members of the classroom community'. This definition emphasises both the local level of norms and the joint construction of norms considered in a CA approach.

Sociomathematical norms are 'the normative aspects of mathematical discussions that are specific to students' mathematical activity' (Yackel \& Cobb, 1996, p. 458). However, the distinction between social norms and sociomathematical norms is not always so clear (Sekiguchi, 2006). What is it that makes an explanation mathematical rather than just an explanation? Most studies rely on what teachers explicitly state what they consider to be a mathematical explanation (e.g. Levenson, Tirosh, \& Tsamir, 2009) or what the researchers themselves consider to be mathematical, or not. From an ethnomethodological approach what matters is what the participants themselves treat as an explanation as they interact, and consequently the distinction between an explanation and a mathematical explanation is not often made (Ingram, Andrews, \& Pitt, 2019).

An ethnomethodological approach, such as the conversation analytic one taken in this paper, views norms (and knowing) as continually negotiated in interaction. Additionally, participants, norms and contexts are mutually shaped through interaction. Whilst norms are actively negotiated by teachers and students, they may not be conscious of these norms until they are breached (Herbst \& Kosko, 2013; Heritage, 1984b). Mehan and Wood (1975, pp. 75-76) describe norms as intertwined with the participants and the current definition of the situation where 'no single one of these can be abstracted out of and treated as either cause or effect'. From this perspective, norms are treated as an 'accountable moral choice' (Heritage, 1984b, p. 76), rather than as behavioural constraints. Classroom interactions are complex and involve many different individuals, yet the majority of interactions run smoothly because of the takenfor-granted norms that allow us to make sense of each other as we interact.

A CA analysis is interested in how these taken-for-granted norms are co-constructed in interaction. In this paper, the focus is on the norms around claims of epistemological 
disalignment and how these are treated by both teachers and students in whole class interactions, and consequently which types of claims are acceptable and which are not, depending on the sequential context. We are interested in how teachers and students come to treat something to be taken-as-shared knowledge, or collective knowing (Staats \& Batteen, 2010). Here, the phrase taken-as-shared is used in the same sense as Cobb, Stephan, McClain and Gravemeijer (2001) to reflect the idea that in interaction practices can be treated-asshared whilst still allowing individual students and teachers to have different meanings and ways of participating in these practices. These norms around claims of epistemological disalignment are of particular interest in classroom interactions as whilst in ordinary conversations claims of not knowing are often accompanied by accounts for why a non-answer is given (Heinemann, Lindström, \& Steensig, 2011), in the examples given below no accounts are given. This suggests that in the context of classroom interaction where knowing is often the goal of interactions, claims of insufficient knowing, and claims of epistemic disalignment more generally, are treated differently to those given in ordinary conversation.

\subsection{IRE}

The IRE or IRF sequence of interaction is widely discussed and debated within the mathematics education literature and beyond, and continues to be a prevalent structure within classroom interaction (Hogan, Rahim, Chan, Kwek, \& Towndrow, 2012). The teacher initiates (I) the sequence, often by asking a question, a student then responds $(R)$ before the turn returns to the teacher who then gives feedback $(F)$, follows up $(F)$ or evaluates $(E)$ the student's response (Cazden, 2001; Mehan, 1979a). This pattern of interaction also occurs in pedagogic interactions outside of the classroom such as everyday interactions where one of the purposes of the interaction is learning (Drew, 1981). The IRE pattern is a structure of interaction that can be, and is, used in a variety of ways. However, it is sometimes treated synonymously with the 'recitation script' (Alexander, 2005) where the I turn consists of closed teacher questions that only requires students to recall simple information or demonstrate their knowledge, which they do in the R turn, and then the teacher assesses the accuracy of this recall in the E turn. Having said this, students are adept at responding to teachers who ask closed questions that they already know the answer to, and this is established as a norm of classroom discourse in many classrooms.

Roth and Gardener (2012, p. 336) argue that the IRE sequence is an important tool for teaching and learning, and this is echoed by Wells (1993), Ingram et al. (2017), and Hogan et al. (2012) who argue that the role and effectiveness of the IRE pattern depends on how it is used, both by teachers and students. Andresen and Dahl (2018), for example, identify what they call 'captivating dialogue' where the questions in the initiation turn are not about checking what students know and the evaluation turn is used to include students in the joint activity rather than to assess students' contributions. The cumulative sequencing of IRE patterns can also influence the nature of learning (Hogan et al., 2012). For example, a sequence may begin with a few initiations that require students to recall facts and knowledge but this serves to make this knowledge public and later initiations in the sequence may then ask students to use this knowledge to make connections, generalise to more abstract relationships, or consider the validity or applicability of such knowledge in different mathematical contexts.

How the IRE pattern is used also influences the epistemic negotiations within interactions. For example, Lefstein and Snell $(2011$, p. 170) argue that the initiation "positions the teacher as the sole legitimate source of knowledge" which is reinforced by the evaluation turn that assess 
the student's response. Yet as Byun (2019) and Ingram (2012) show, teachers can ask questions in the initiation turn that treat the student as being the source of knowledge. Many of the claims of not knowing or not remembering discussed below occur within this IRE pattern.

\section{Theoretical Perspective}

The analysis in this paper takes a CA approach, grounded in ethnomethodological principles (Ingram, 2018). CA is a data-driven micro-analytical approach to the analysis of naturallyoccurring interactions. One aim of CA research into classroom interactions is the documentation and description of micro-moments of interactional displays of knowing, learning and understanding taking an emic perspective which emphasises the participants' own understanding of the interaction as revealed in the structure and content of their turns at talk. Thus, the meaning of a particular utterance is considered within the sequential context in which it occurs, examining the previous turns it is responding to and the actions it is inviting in the turns that follow (Barwell, 2018; Schegloff, 2007). CA treats all turns as social actions, and turns can perform several actions depending on the interactional context in which they are used. A student saying 'I don't know' can request help from the teacher or another student, it can also initiate a complaint about a teacher's explanation, or it could be a resistance to answering a question posed by the teacher (Lindwall \& Lymer, 2011). Claims of not knowing, not remembering or not understanding could also originate from difficulties with articulating or using the language and representations of mathematics rather than a difficulty with the mathematical content. These students may still be engaged in mathematical thinking but are unable to express this through language (Moschkovich, 2015). In the context of this paper, claims such as 'I don't know' or 'I don't remember' can consequently mean and do different things depending on their position within the sequence of interaction.

The interest in and the focus of any analysis is of social actions from the perspectives of the teachers and students in the interactions. Consequently, classroom norms are joint accomplishments by teachers and students and are patterns or routines of interactions that occur in interaction that teachers and students draw upon to make sense of each other but not necessarily consciously (Mehan \& Wood, 1975). It is these unnoticed or taken-for-granted patterns or norms which are the main interest of CA research.

One of the basic building blocks of interaction is referred to in CA as an adjacency pair (Drew, 2013). These are two sequential turns where the first turn (called the First Pair Part or FPP) makes the second turn (the second pair part or SPP) conditionally relevant (Ingram, Andrews and Pitt, 2019). A question makes an answer conditionally relevant in the turn that follows; a request makes an acceptance conditionally relevant. An IRE sequence consists of two intertwined adjacency pairs, the initiation (FPP) and the response (SPP) and the response (FPP) and evaluation (SPP) (Mehan, 1979a; Schegloff, 2007).

Within this structure certain SPPs are preferred over others where the term preference refers to the structure of the SPP rather than any affective reaction. A preferred SPP is usually given quickly and in an unmarked way and closes the sequence, whilst a dispreferred SPP is usually given hesitantly, includes makers such as a rising intonation, and often includes an account for why the preferred response has not be given. The preferred response to a teacher's question is usually (but not always) the correct answer to that questions, whereas non-responses or claims of not knowing the answer are usually dispreferred. A preferred SPP is often identifiable by being 'noticeably absent' when it does not occur (Bilmes, 1988). As Stivers and Robinson 
(2006) state a non-answer response (such as 'I don't know'), whilst it is a 'normatively viable action in response to a question, it is a dispreferred alternative' (2006, p. 371).

The evaluation turn has received the most attention from conversation analytic approaches. Hellermann (2003) and Macbeth (2004) showed the different uses of teachers' repeating the student answers where the prosody or modification of the repeat makes the distinction between an acceptance of the student's answer, and a rejection of the student's answer. Other research has considered how incorrect answers are treated in mathematics classroom interaction using a CA approach. Tainio and Laine (2015) identify seven types of teacher evaluations including redirecting the next turn to another student, or repeating the question where the different types of evaluation can be combined. Both this research and that by Ingram, Baldry and Pitt (2015) focus on how teachers display their stance towards student mistakes in their treatment of these mistakes in interaction.

Another key idea within CA is what Schegloff (2007) calls the progressivity of interaction, where the speaker is doing something with their turns at talk and are building a sequence of actions. Krummheuer and Brandt (cited in Krummheuer, 2015) also use this idea, describing it as the 'smooth course of interaction'. For example, a question in the FPP (or I turn) makes an answer conditionally relevant, and giving the preferred answer furthers the progress of the activity being done in the interaction. However, responding with a non-answer such as 'I don't know' does answer the question but does not further the progress of the activity. In interaction there is generally a preference for the smooth progressivity of interaction. This progressivity of interaction means that there are no 'interactional difficulties' such as interruptions, disagreements, silences, or non-answer responses.

\subsection{A CA approach to the study of epistemics}

From a CA perspective learning is seen as emerging from interaction and participation, not as a cognitive, individual phenomenon. For example, CA examines how actions such as establishing, eliciting, or claiming access to knowledge are managed in interaction, that is how participants take into account the knowing and unknowing participant (Heritage, 2012a). In doing so it deals with issues of who has, or could be expected to have, access to the knowledge of interest. Epistemic asymmetry can be considered to be a defining property of classrooms (Solem, 2016), and the prevalence of the IRE sequence illustrates this. The teacher has the right to ask questions but also the responsibility to respond to students' answers and to students' questions. Teachers also have the right to ask questions that they already know the answer to (Mehan, 1979b). Given that a fundamental institutional goal of classrooms is learning and gaining knowledge it is not surprising that interactional displays of knowing, understanding and remembering frequently occur in classroom interactions.

Recent CA research has examined the role of knowledge in the organisation and structure of a range of interactions (Heinemann et al., 2011; Heritage, 2012b, 2012a; Heritage \& Raymond, 2005, 2012; Kämäräinen, Björn, Eronen, \& Kärnä, 2019; Keevallik, 2011; Raymond \& Heritage, 2006; Stivers, Mondada, \& Steensig, 2011). Their analysis often focuses on how different participants may orient to differences in what people do or do not know, or claim to know (or not know). Heritage (2009) distinguishes between different positions of epistemic access between participants in interaction, where $\mathrm{K}+$ participants are more knowledgeable and $\mathrm{K}$ participants are less knowledgeable. Epistemic status is therefore related to the relative access participants have to the knowledge being drawn upon in the interaction. This initial research has led to a range of studies examining epistemic management in ordinary conversation, 
including claims of insufficient knowledge in interaction (Heinemann et al., 2011; Keevallik, 2011). Research focusing on classroom interaction largely examines English language lessons (e.g. Jakonen, 2014; Sert \& Walsh, 2013), but some recent works within mathematics education (e.g. Kämäräinen et al., 2019; Koole, 2012a, 2012b) illustrate the negotiation of epistemic access and responsibilities as described below.

Stivers, Mondada and Steensig (2011) outline three primary dimensions of epistemic management that need to be considered in any analysis, as they are treated as relevant by participants themselves in interaction. These are epistemic access, epistemic primacy (or rights) and epistemic responsibility. These dimensions are routinely managed by participants in interactions.

Epistemic access is concerned with who can be expected to have access to the knowledge being considered. Students and teachers often have shared experiences of mathematics drawn from previous lessons and tasks that have been assigned by the teacher and completed by the students. Consequently, in interaction teachers and students can treat these experiences as common or shared (Cobb et al., 2001; Edwards \& Mercer, 1987), that is both students and teachers have access to this knowledge. This is particularly evident in the nature of questioning common to classrooms. In ordinary conversation, questions are usually information requests, which treat the recipient as knowing that information but the questioner as not knowing by wanting that information. In contrast known answer initiations (Mehan, 1979b) often found in classrooms treat both the teacher and the student as knowing. Posing a question to a particular student presupposes both that the student has access to the answer, but also the willingness to answer the question.

Epistemic primacy refers to how participants orient to the epistemic asymmetries such as their rights to tell, know or assert knowledge. Classrooms are structured around institutional roles relating to epistemic access and rights. Teachers are expected to have access to the mathematical knowledge that students are learning, and this role carries with it the right to tell and assert this knowledge. Yet teachers do not have absolute epistemic primacy (Stivers \& Rossano, 2010) as students can also contribute knowledge that might be unknown to the teacher (see for example Byun, 2019).

Epistemic responsibility on the other hand, refers to how participants can be held accountable for knowing or not knowing. Interactants treat themselves as responsible for being able to answer a question addressed to them, and provide accounts when they cannot. In interaction the common knowledge that members of the classroom share through previous experiences means that teachers can treat students as responsible for knowing and retaining what they have come to know. In this paper we consider how these epistemic dimensions, and in particular epistemic responsibility, are made visible through how students' claims of epistemological disalignment are handled in interaction.

Koole's (2012a, 2012b) analysis of epistemic management within interactions in multilingual mathematics lessons reveals how teachers treat what students say in terms of knowing, doing or understanding in ways that do not necessarily align with the epistemic claims being made by the students. For example, he showed how positive assessments largely focused on students' knowing and this knowledge was subsequently something that could be built on, whereas negative assessments largely focused on what students had done. Evaluations of understanding were only negative in his corpus. Kämäräinen et al.'s work (2019) focuses on peer interactions when working on mathematical tasks and contrasts situations where $\mathrm{K}+$ and 
$\mathrm{K}$ - positions are accepted by the students with situations where these positions were challenged, contested and defended. These studies all illustrate how teachers and students orient to and negotiate differences in what people do or do not know, or claim to know in relation to mathematical tasks.

\subsection{Alignment and affiliation}

When students respond to a teacher's initiation, whether the response is acceptable or not is not solely based on whether a response is correct (or not). Whilst a student's inability to answer a question could be seen as a difficulty in their knowledge or understanding, it could also be seen as an obstacle to the smooth progression of the interaction. Stivers (2008) conceptualises alignment as the structural level of cooperation, i.e. aligning turns enable the proposed activity or sequence such as by matching the design preference of the turn, and affiliation as the affective level, where actions match the previous speaker's evaluative stance. A disaligning action includes interruptions and requests for clarifications for example. Disaligning actions can be either affiliative or disaffiliative, and though affiliation is not always relevant in everyday interactions, it is in the classroom. Answers can align or disalign, and be affiliative or disaffiliative, and preference for aligning and affiliative responses is normative and moral (Stivers, 2011). Disaffliative responses, such as a disagreement, can be simultaneously aligning in that they can move the sequence forward. The teaching strategy where a teacher treats an incorrect response as correct in order to encourage students to disagree and explain why the response is incorrect would be one example where a student disagreeing with a previously given answer is aligning with the teacher's trajectory, whilst being disaffiliative towards the student who gave the initially incorrect response (Ingram et al., 2015). Antaki (2012) provides further examples where demonstrations of understanding or not understanding can be disaffiliative and become an obstacle to the progressivity of the teacher's actions. In this paper the phrase claim of epistemological disalignment is used to capture student turns where in the interaction the teacher has treated them has having the knowledge or understanding but the student is indicating that they do not have this knowledge or understanding.

\subsection{Claims and demonstrations}

Sacks (1992), one of the founders of CA, makes a distinction between demonstrations and claims which was used in Koole's $(2010,2012 \mathrm{~b})$ analysis of the classroom management of epistemic displays in mathematics classrooms. A claim of understanding says nothing about what the speaker does or does not understand. In classrooms teachers frequently ask questions like 'does everyone understand' to which the usual response is 'yes'. This 'yes' is a claim of understanding. A demonstration of understanding includes some information about what has been understood. Repeats or partial repeats of what someone has said are examples of demonstrations of (not) understanding. This is a common feature of the teacher's E move which often includes some form of repetition of the student's $R$ move and this demonstrates the teacher's understanding of the student's turn.

Koole (2010) details the differences between students' displays of understanding and displays of knowing following a teacher's explanation when working individually, as well as differences in the preference organisation of claims and demonstrations of knowledge by students. He showed that 'do you understand' questions occurred in sequential contexts where a claim of understanding is preferred. In contrast, 'do you know' questions occurred in contexts where a demonstration of knowing is preferred. Similarly, Ingram and Andrews (2019) showed how claims of understanding in mathematics classroom interaction support the progressivity of the 
interaction, and are consequently affiliative. Demonstrations of understanding were followed by the expansion of the IRE sequence in order to work with the contents of the demonstration with the student making the demonstration. Claims and demonstrations of understanding generally occurred when the teacher had explicitly asked for the student to demonstrate their understanding within an IRE pattern. As shown below, this is not the case for claims or demonstrations of not understanding.

\section{Methods}

This research draws from data collected in three previous studies. The data consists of video recordings from mathematics classrooms in 8 different schools in England. The entire data-set contains 42 lessons of between 45 minutes and 120 minutes in length. The lessons come from 17 teachers and the students are aged between 11 and 18 years old. The 8 schools include schools with very high and very low levels of social deprivation, high and low numbers of students for whom English is not their first language, and a range of performances in national league tables. The classes included top sets (it is common to group students by prior attainment in England), mixed attainment classes, and bottom sets, as well as classes studying advanced mathematics beyond the point at which it is compulsory (aged 17-18). This enables the identification of patterns of interaction that specifically relate to the teaching and learning of mathematics, rather than to particular groups of students or teachers. The lessons were naturally occurring (Ingram \& Elliott, 2019) in that the teacher was not asked to teach in a particular way and in each case the teacher chose which lesson to video record. The focus of two of the studies was on whole-class interaction and consequently group work and individual student-teacher or student-student interactions were omitted from the data collection, therefore the analysis for this paper focused on whole-class interactions. This resulted in over 14 hours of whole class interactions which was included in the analysis.

\subsection{Collecting cases}

As is common for CA studies, the analytic process began with the unmotivated examination of the video recordings (Psathas, 1995, p. 45), and then after initially noticing the rarity of students' claims of not understanding, a collection of cases (Sidnell, 2010) of students' turns that included claims or demonstrations of epistemological disalignment such as not knowing, not remembering or not understanding was built. The cases focused on students' claims or demonstrations of not knowing, not remembering or not understanding with an aim of understanding the ways in which these claims are managed in classroom interaction. These cases were collected by identifying interactions where students used phrases such as 'don't know', 'no idea' as well as content specific claims such as 'that doesn't make sense'.

Additionally, all interactions where students used the words know, understand, remember, sense, meaning were considered and included if they were used to make a claim of not knowing or not understanding. This resulted in 62 cases that could be categorised as claims or demonstrations of not remembering (including phrases like "I forgot"), not knowing (including phrases like 'I have no idea'), or not understanding (including phrases like "I don't get it"). The cases shown in the results section below are representative of the cases in the final collection of cases where students make claims or demonstrations of epistemological disalignment. They were selected because they are particularly clear examples of the phenomenon being discussed. Two cases where the phrase "I don't know" was accompanied by an answer to the question, and where the teacher ignored this part of the student's turn were classified as hedges in the sense of Rowland (1995), not as claims of epistemic disalignment since the rest 
of the student's turn aligned with the teacher's question and the teacher did not treat the turn as disaligning or disaffiliative.

\subsection{Analytic approach}

The data were analysed using conversation analytical tools (see e.g. Sidnell \& Stivers, 2012) such as those outlined in section 3 , focusing on the close, micro-analytic sequential analysis of turns rather than isolated turns. The whole-class interactions were transcribed using the Jefferson transcription system (Jefferson, 2004) (see Section 7 for information on transcription conventions). In a CA approach identities or roles such as teacher or students are not normally identified in transcripts, unless the interaction itself makes these roles relevant to the interaction. In all the cases considered the epistemic management and the frequency of cases following the IRE structure makes these roles relevant to the structure of the interaction. Consequently, all teachers have been given pseudonyms beginning with the letter $T$ and all students have been given pseudonyms beginning with the letter $\mathrm{S}$. Other attributes of the teachers and students, such as gender, race or age, are not included as they are not made relevant in the sequence of turns making up each case themselves by the participants.

The analysis of the collected cases focused on the following questions:

1) How are students' claims of not knowing, not remembering or not understanding treated in whole class interactions?

2) How does the teacher's treatment of students' claims of not knowing, not remembering or not understanding depend upon the construction of the claim?

\section{Results}

This section begins by examining the interactional treatment of claims and demonstrations of not knowing, not remembering or not understanding made by students. Claims and demonstrations of these cognitive states perform different social actions and are consequently treated differently in classroom interactions.

\subsection{Claims of not remembering}

When students make a claim of not remembering following a teacher's question, this claim is accepted by the teacher who redirects the question to another student. For example, in Extract 1 Trish has asked Seth a question relating to calculating the original temperature when the temperature change is $-30^{\circ} \mathrm{C}$ and the final temperature is $-40^{\circ} \mathrm{C}$. After two long pauses of 2.4 seconds each, Seth begins his response hesitantly before stating that he 'can't remember' and in the turn that follows the teacher redirects the question to another student.

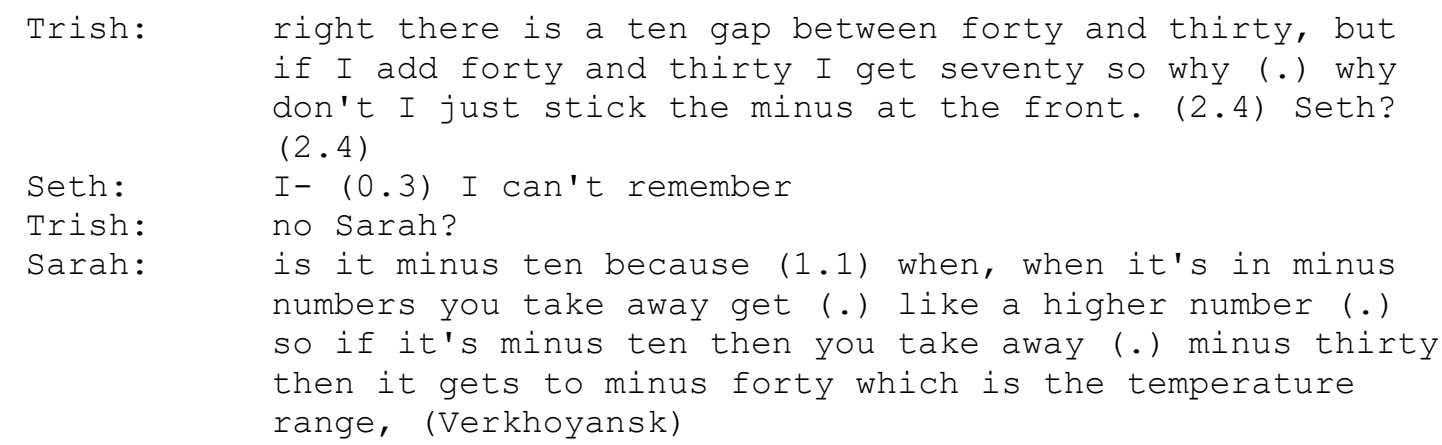

Extract 1: FD010709 Student claim of not remembering

Something similar happens in Extract 2 where Thea has asked Shane a question which requires him to revisit a statement he made about what the difference between an edge and a diagonal 
on a diagram of an arrowhead with the diagonals drawn in. Shane initially responds with 'I don't know' before changing this to 'I can't remember'. Again, in the following turn the teacher redirects the question to another student.

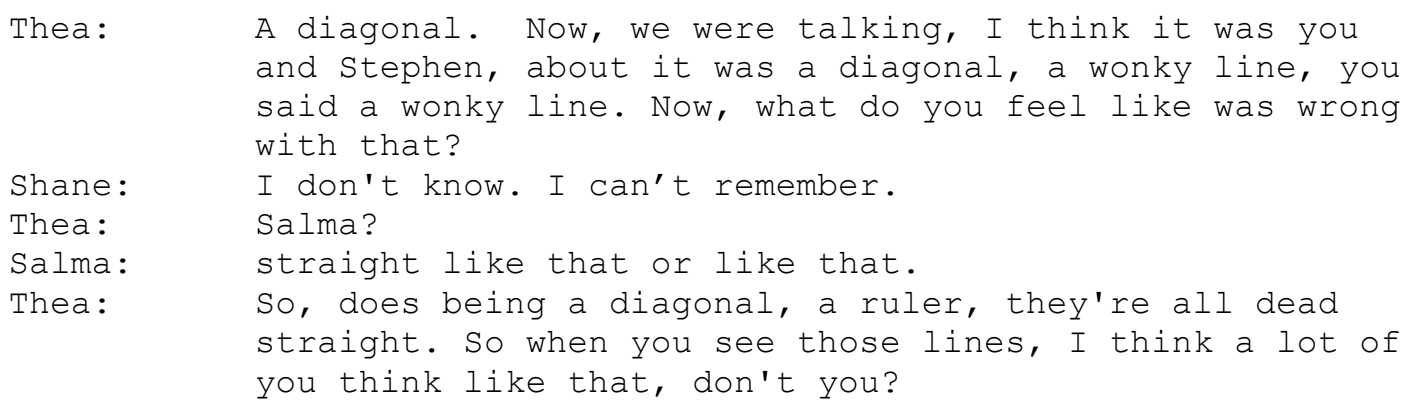

Extract 2: LH030317 Student claim of not remembering

In every case where a student makes a claim of not remembering the teacher redirects the question to another student in the following turn. The teacher continues to pursue an answer, but from another student. Teachers usually know the answers to their questions and are in a $\mathrm{K}+$ position in these situations. Consequently, when they ask these questions they are requesting students to demonstrate their knowledge. That is, the knowledge being discussed is treated as shared by the teacher and the students and the teacher is treating the students as also in a $\mathrm{K}+$ position. A claim of not remembering shows that the student accepts that this knowledge is shared by them with the teacher, but that they cannot remember the knowledge, rather than they do not have access to the knowledge. This maintains the $\mathrm{K}+$ position of the student even though the student has not demonstrated this knowledge. In this sense, a claim of not remembering whilst not aligning with the teacher's question, is affiliative and the student is accepting responsibility for not giving an aligning answer as it is them that has forgotten the knowledge in this moment. By asking another student in the interaction that follows, the teacher continues to treat this knowledge as shared and pursues an aligning response.

\subsection{Claims of not knowing}

Claims of not knowing, on the other hand, challenge the idea that the knowledge is shared between teachers and students. In Extract 3, Trish asks a binary question giving Simon a choice of two possible answers, plus five or minus five degrees. Simon initially responds hesitantly before making a claim of not knowing, which he then upgrades to 'really' not knowing.

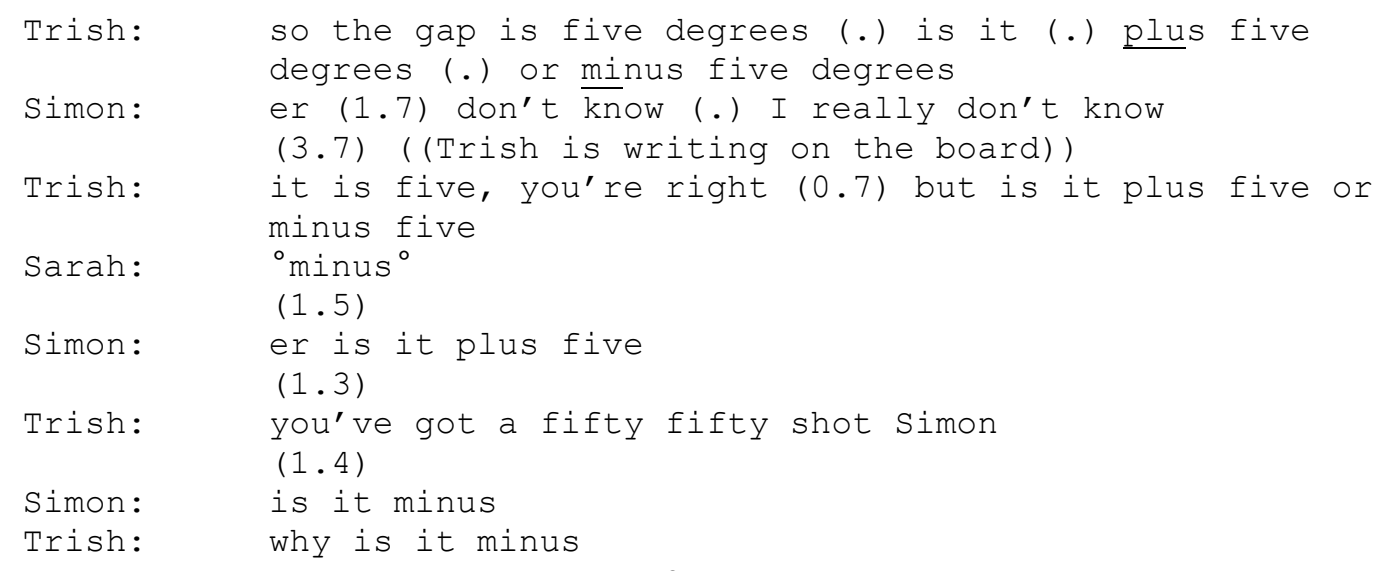

Extract 3: FD010709 An emphatic claim of not knowing. 
Trish continues by repeating the question, but this time begins with a positive assessment of Simon's earlier answer of five degrees. Trish is thus treating the difficulty as one of Simon not being confident that the answer is five degrees rather than an issue of not knowing. Simon hesitantly offers an answer of plus five, which Trish does not accept, instead she reinforces the binary nature of the question, inviting another answer from Simon. The absence of an acceptance of Simon's answer of plus five and the emphasis of the answer being one of two options with a fifty-fifty chance of getting the answer correct if you just randomly guess effectively treats Simon's answer of plus five as incorrect (Ingram et al., 2015). In contrast, when Simon then answers hesitantly with 'is it minus', Trish responds immediately and moves on to a new question, an indication that Simon's new answer has been accepted (Margutti \& Drew, 2014). Throughout this interaction Trish has continued to treat Simon as being able to answer the question, as being in a $\mathrm{K}+$ position, not accepting his claim of not knowing. This continues to be the case in Trish's final question where, having established that the answer is minus five degrees, she then returns to Simon to ask why the answer is minus five degrees.

In Extract 4 the interaction again begins with a binary question asking students to choose between indirect or direct proportion. Scott responds with indirect which Tyler immediately follows up with a question of why the answer is indirect. Scott indicates that he has understood that his response requires an explanation by beginning his turn with 'because' (Ingram et al., 2019) before claiming that he does not know.

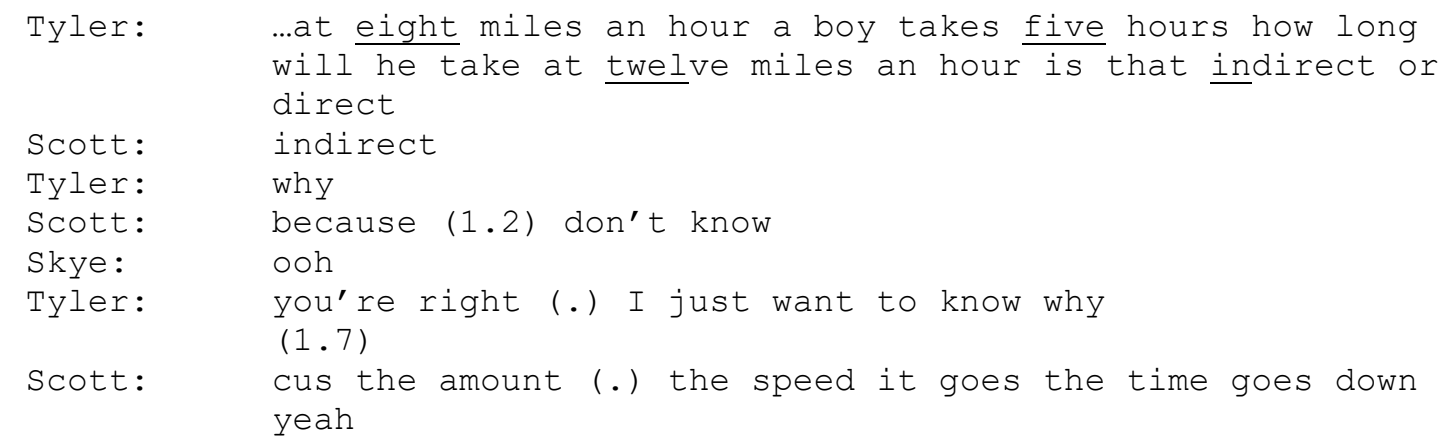

Extract 4: JC250609 Claim of not knowing

In a similar way to Trish in Extract 3, Tyler begins his subsequent turn with a positive assessment of Scott's previous answer of 'indirect', before asking for the explanation again. This is followed by a long pause of 1.7 seconds which gives Scott time to think and construct his answer, and subsequently he gives the required explanation in the following turn. Again, whilst Scott has made a claim of not having access to the knowledge needed, as being in a Kposition, Tyler continues to treat Scott as being able to answer the question, as having the required shared knowledge $(\mathrm{K}+)$, and in this instance the extract ends with Scott's demonstration that he does indeed have access to this knowledge.

Claims of not knowing challenge the assumption made by the teacher that the student has access to the knowledge required to answer. Whilst the teacher is treating the students as being in a $\mathrm{K}+$ position, the students challenge this and position themselves as being in a $\mathrm{K}$ position. In this respect these claims are disaffiliative as well as not aligning with the expected response. In challenging this assumption, the students are putting the responsibility for knowledge with the teacher and are claiming that they do not have access to the required knowledge which the teacher has treated as shared. The institutional role of teacher includes responsibility for ensuring students have access to the knowledge that they need, and consequently by making a claim of not knowing, students are indicating that this is the 
teacher's fault (Heinemann et al., 2011). In the two extracts above the teacher has not accepted the students' claims of not knowing, and in doing so are asserting that they have fulfilled their responsibility as the teacher and that in fact the students do know.

Another way that teachers respond to students' claims of not knowing is by treating them as an issue of remembering rather than knowing. In Extract 5, the class are identifying the mistakes given in example answers to examination questions as part of a revision lesson. Tara has asked Susie to identify one of the mistakes. Susie responds with a claim of not knowing which Tara treats as an issue of not remembering in the turn that follows.

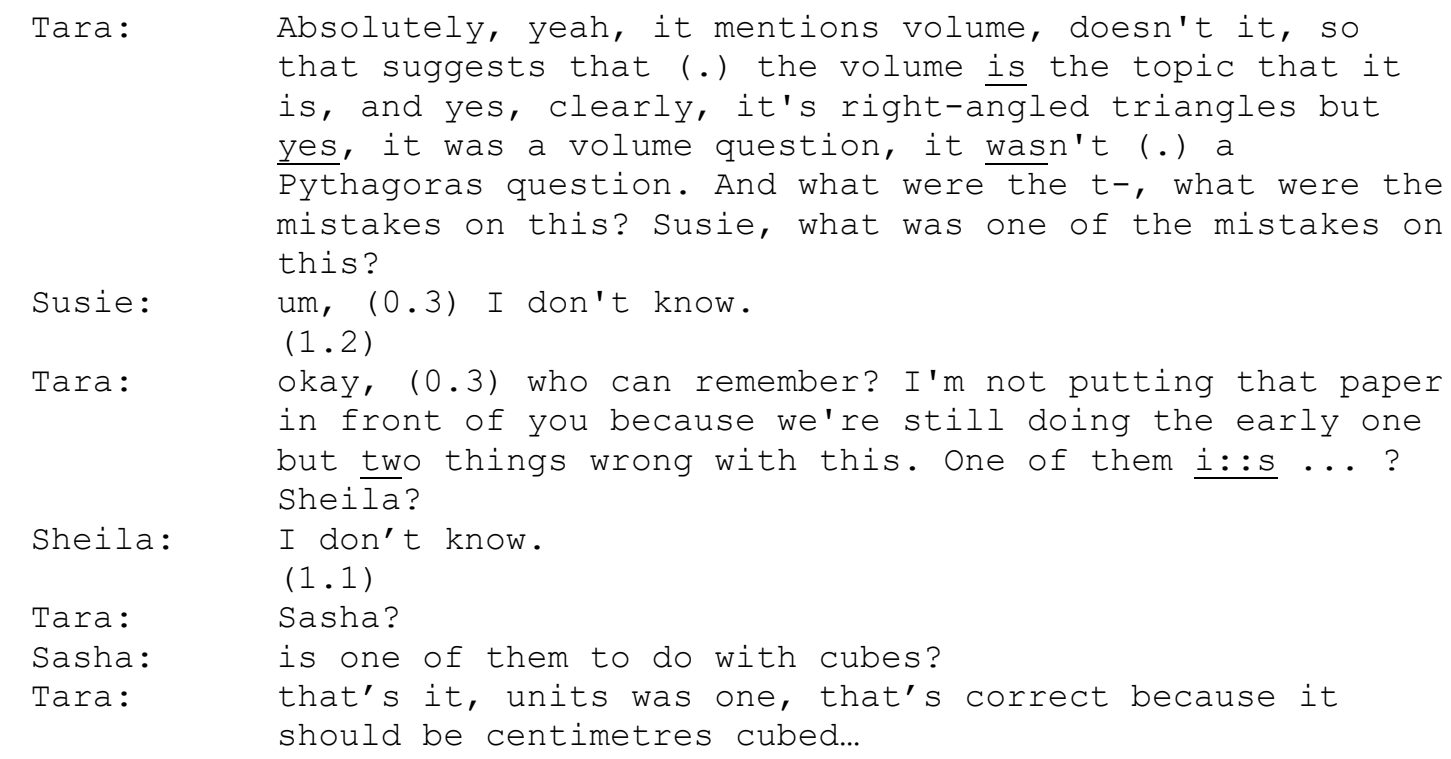

Extract 5: AH010216 A claim of not knowing treated as one of not remembering

In Tara's treatment of Susie's issue as being of one about remembering she references the copy of the answers to the exam questions in paper form that the students do not currently have access to. Tara is referencing a shared resource that the students have previously had access to, and consequently is reinforcing the assumption that the knowledge needed to answer the question is shared, but that the students may need the paper form in order to remember it. In a similar way to the previous extracts, Tara maintains the assumption that the students have access to the knowledge needed to answer the question and that the responsibility lies with the students to remember this knowledge. In contrast both Susie and Sheila assume a K- position and challenge the notion that the knowledge is shared.

In each of the extracts above the students' claims of not knowing do not include any additional actions that could mitigate the disaffiliative nature of a claim of not knowing. In contrast, in Extract 6, the claim of not knowing is preceded by an attempt to answer the question.

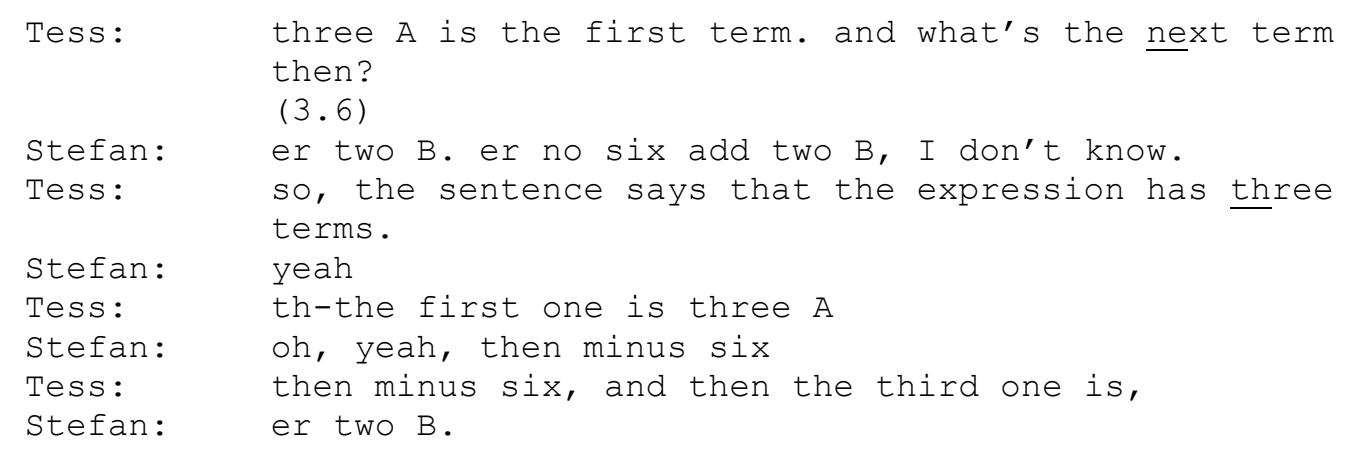




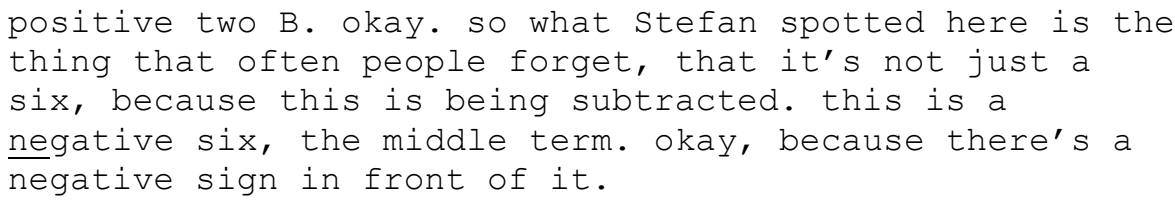

Extract 6: FB190117 Claim of not knowing with attempt to answer

Stefan initially offers two potential answers to Tess' question before making a claim of not knowing. These two potential answers demonstrate that Stefan knows what the question is asking, and the claim of not knowing also functions as a hedge for his previous answer (Rowland, 1995). Tess does not accept either of Stefan's answers and instead she reads the question out from the beginning. In doing so, Tess is restating the shared knowledge as all members of the classroom have access to the question displayed on the whiteboard. She then repeats her earlier assertion of $3 A$ as the first term of the expression. At this point, Stefan gives a change-of-state token 'oh' (Heritage, 1984a) and follows this with the answer Tess is looking for. Tess accepts this answer by repeating it and asking a follow-up question (Margutti \& Drew, 2014), which Stefan then answers.

In all of the cases where students have made a claim of not knowing, the teacher has continued to treat the knowledge needed as shared, and has persevered with the student who has made the claim of not knowing until they have successfully demonstrated the knowledge required. The only exceptions are where the teacher treats the issue as one of remembering rather than one of not knowing, as in Extract 5, where the subsequent interaction then follows the structure of turns that follow a student claim of not remembering outlined in Section 5.1. The teachers do not accept students' claims of not knowing, but do accept students' claims of not remembering. Neither claims of not remembering or claims of not knowing give the answer to the question that the teacher is seeking, that is they do not align with the question asked. However, a claim of not remembering is affiliative in that the student accepts responsibility for not giving an aligned response. On the other hand, a claim of not knowing is disaffiliative as it places the responsibility for the student not giving an aligned response on the teacher. These differences in affiliation are revealed in the interaction that follows, where affiliative responses are accepted and disaffiliative ones are challenged with the teacher continuing the interaction until the student making the claim has given an aligning response, or the teacher treats the disaffiliative claim of not knowing as one of not remembering, which is an affiliative claim. In all the examples given, the teacher pursues the question until the required response is given.

\subsection{Claims and demonstrations of not understanding}

In contrast to claims of not knowing or claims of not remembering, claims or demonstrations of not understanding do not occur in response to a teacher's question and are very rare in the whole class interactions considered in this paper. There are only 2 claims of not understanding and 4 demonstrations of not understanding across the 42 lessons. In five of the cases, the teacher accepts that there is an issue of not understanding but treats the issue as being specific to the student making the claim or demonstration and delays dealing with the issue until they can speak one-to-one with the student once the rest of the class is working individually.

Tristin: numbers pick one of the numbers as a value for $\mathrm{n}$. work out the missing numbers, using the same shape, apply that rule to somewhere else, see if you can add them up to be um using this rule like this one if I draw that $C$ anywhere else I should find that I get er five $n$ add two 
will tell me, if I draw a C in here, er draw this c in

one two three four five. five times thirty-two is a

hundred and sixty, add two makes a hundred and sixty-

two. Steve

Steve: I don't understand

Tristin: okay I'll come and see you. it will be seven minutes, to have a go, starting now.

Extract 7: ST151013 Claim of not understanding

In Extract 7, Steve has his hand raised but is not responding to a question posed by Tristin.

When Steve is invited to take the turn, he gives a claim of not understanding but no indication of the nature or focus of what he is not understanding. Tristin accepts this claim by stating that he will come and speak to Steve before setting the rest of the class off on the task he has just introduced. In Extract 8 Sophia makes a demonstration of not understanding 'how it works'. Toby has handed out a worksheet with a list of linear equations to solve following an interaction where the class has worked through how to solve $3 x-5=10$ using function machines. In the interaction immediately before the extract, Toby has invited questions from the class and one student has asked a question which is then answered by Toby. Toby then indicates that he is ready to move on before Sophia gives a demonstration of not understanding.

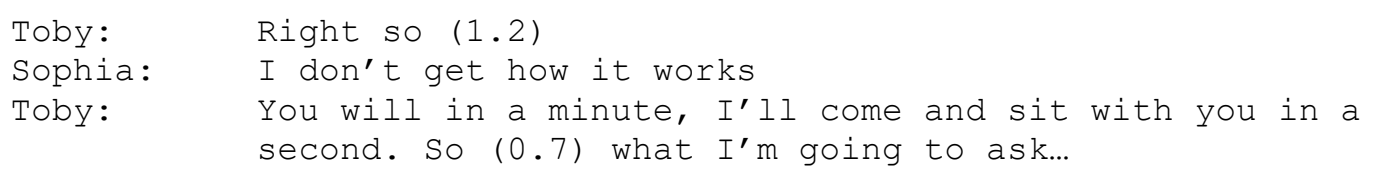

Extract 8: KR120516 Demonstration of not understanding

Sophia's demonstration tells us something about what she does not understand, but not much. In the same way as in Extract 7, Toby indicates that he will work with Sophia on a oneto-one basis before addressing the whole class and returning to the topic of the task that he wants the class to address.

In both Extracts 7 and 8 the teacher treats the claim of not understanding as something that will be dealt with, but not in the immediate interaction. In contrast, in Extract 9 Sarai has asked a question about one of the questions on a worksheet the class have been working on and Todd has just finished going through the answers for with the class. Sarai ends her turn with a claim of not understanding. In this extract, Todd deals with the issue immediately, but treats the issue as one of not remembering by recounting the lesson in which the students had gained experience of working out the equation of a straight line from its graph using graphing software. He then summarises the outcome of the lesson in terms of where to write the gradient and the $y$-intercept, which had already been calculated for this particular question as Todd went through the answers earlier in the interaction.

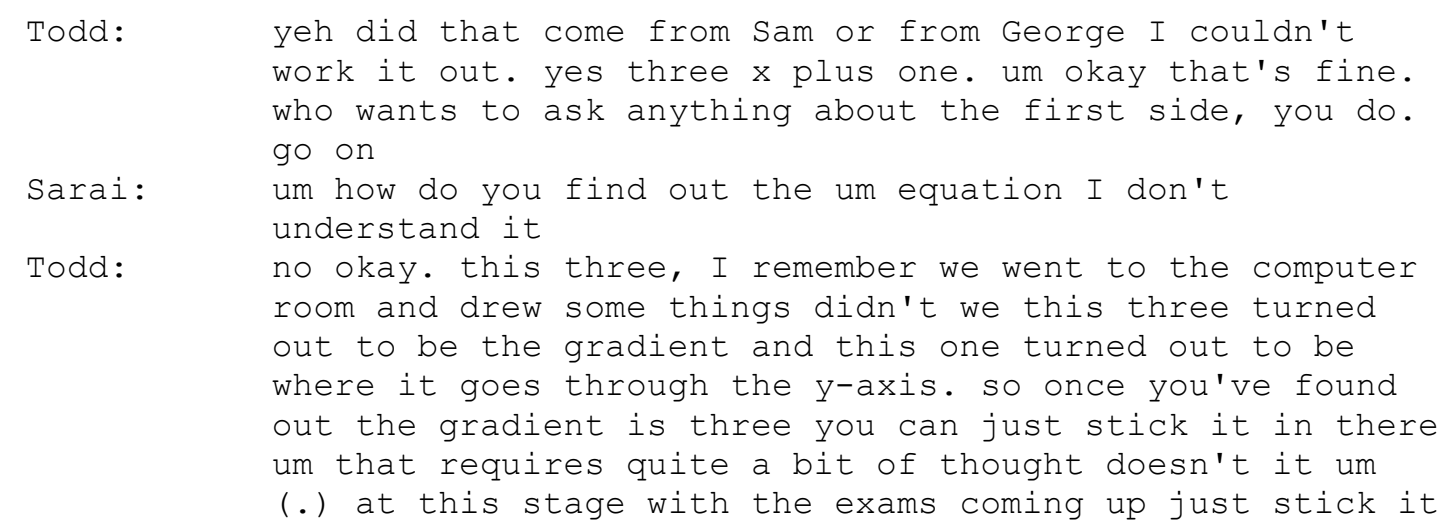




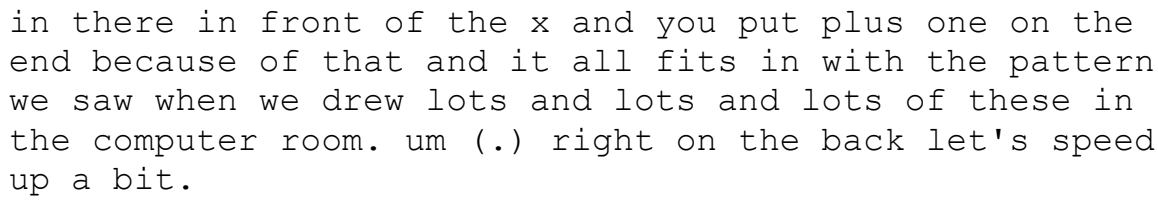

Extract 9: DG270408 Demonstration of not understanding in response to a teacher request

In contrast to Extracts 7 and 8, Todd deals with the issue of not understanding immediately in the interaction, and treats it as an issue of not remembering. Todd's response points to a shortage of time twice, once in reference to how close the class are to their exams and once at the end where he expresses a need for the pace to speed up. Issues of not understanding are treated by all the teachers as issues that will take time to resolve. The first two teacher's respond to this by delaying their dealing of the understanding issue. Todd, in Extract 9, deals with the issue immediately but this leads to a relatively lengthy explanation that focuses on where the students were given access to the knowledge needed to make sense of the question and to 'understand' what the gradient and y-intercept are. Todd is treating the understanding as shared from the lesson where they examined gradients and intercepts using graphing software, and contrasts this with the knowledge of 'just stick it in there' in terms of which number is the gradient and which is the y-intercept.

\section{Conclusion}

Student claims of epistemological disalignment occurred in a very narrow range of sequential contexts within the data considered. Each claim of not remembering or not knowing occurred during the $R$ turn of an IRF sequence, where the I turn involved a known-answer question. This in itself is interesting as it would appear that claims of not knowing or not remembering are only relevant to sequential contexts where the teacher has asked a known-answer question and the student is treated as being able to answer this question, as needing to demonstrate their knowledge. The teachers' treatments of 'I don't know' suggests that these questions are not solely assessments of the students (so-called testing questions) as a response of 'I don't know' would give, to some extent, the assessment information that the teacher needs in these situations. Rather the response is needed to make the knowledge public so it can be treated-as-shared, and the pursuing of an answer following a claim of not knowing establishes that the knowledge in focus is in fact shared

These teachers' known-answer questions treat students as having access to the needed knowledge as well as having the responsibility to answer the question. Consequently, claims of not knowing are disaffiliative in that they challenge the teachers' treatment of the knowledge as shared, and consequently their responsibility to ensure that the knowledge is shared. In contrast, claims of not remembering do not challenge this assumption and the responsibility for the problem lies with the student.

This study has only considered public claims as they occur in whole-class interactions. The treatment of claims of not knowing or not understanding may be different in private, and small group work as suggested to some extent by Koole (2012b). The findings here also contrast with Sert and Walsh's analysis of EAL classrooms where claims of not knowing were redirected to other students which suggest that the context of the classroom, and potentially the nature of knowledge being negotiated, may influence epistemic management in classroom interactions.

There are also differences in the ways that claims of not knowing or not remembering are treated compared to claims of not understanding. These differences also extend to the 
contrast in frequencies in which each claim occurs. This suggests that issues of knowing and issues of understanding are different interactional concerns within mathematics.

Questions serve different purposes and perform different actions. Both the claims of not remembering and the claims of not knowing follow known-answer questions. In the data considered, claims of not knowing did not occur with other types of questions, such as open questions or questions asking for something the teacher did not know. It would be difficult to claim not knowing if you were describing what you did or what you are thinking, rather than what you know for example. How students are selected to answer questions will also influence the occurrence of claims of epistemological disalignment, as volunteers are unlikely to volunteer a non-answer. Also Jakonen (2014) showed that secondary students were more likely to ask their peers than their teachers for what was needed to address missing knowledge.

Teachers asking questions that they know the answer to is a norm of classroom interaction in many classrooms. Whilst both teachers and students handle these questions in a taken-forgranted way, they can have consequences on the management of epistemic concerns of knowing and understanding. Norms guide what it means to participate and how to participate in the classroom. Yet as the analysis above shows, these known-answer questions serve to make shared knowledge public which enables this knowledge to be built on. So whilst Guizueta (2019) argues that teachers should develop norms where "the communication of epistemic issues is relevant and the disposition to do it is prevalent" (p. 10), norms that do not do this also have a role in the consideration of epistemic concerns in the mathematics classroom.

\section{Transcript Notation (from Sidnell (2010))}

\begin{tabular}{lll} 
Convention & Name & Use \\
\hline text] & Brackets & $\begin{array}{l}\text { Indicates the start and end points of } \\
\text { overlapping speech. }\end{array}$ \\
\hline (0.5) & Timed silence & $\begin{array}{l}\text { Indicates the length, in seconds, of a } \\
\text { silence. }\end{array}$ \\
\hline (.) & Micropause & $\begin{array}{l}\text { A hearable pause, usually less than } 0.2 \\
\text { seconds. }\end{array}$ \\
\hline ? or $\uparrow$ & Period & Indicates falling pitch or intonation. \\
\hline Question mark or & Indicates rising pitch or intonation. \\
\hline Up arrow & Comma & $\begin{array}{l}\text { Indicates a temporary rise or fall in } \\
\text { intonation. }\end{array}$ \\
\hline underline & Underlined text & $\begin{array}{l}\text { Indicates the speaker is emphasizing or } \\
\text { stressing the speech. }\end{array}$ \\
\hline & Colon(s) & Indicates prolongation of a sound. \\
\hline & Dyphen & Indicates an abrupt halt or interruption in \\
\hline
\end{tabular}




(text) Parentheses Speech which is unclear in the transcript.

\section{References}

Alexander, R. (2005). Culture, dialogue and learning: Notes on an emerging pedagogy. Education, Culture and Cogntion: Intervening for Growth. International Association for Cognitive Education and Psychology (IACEP) 10th International Conference, (10-14th July), 1-4. University of Durham, UK.

Andresen, M., \& Dahl, B. (2018). Classroom dialogue as a french braid: A case study from trigonmetry. In E. Bergqvist, M. Österholm, C. Granberg, \& L. Sumpter (Eds.), Proceedings of the 42nd Conference of the International Group for the Psychology of Mathematics Education (Vol. 2, pp. 43-50). Umeå, Sweden: PME.

Antaki, C. (2012). Affiliative and disaffiliative candidate understandings. Discourse Studies, 14(5), 531-547. https://doi.org/10.1177/1461445612454074

Barwell, R. (2018). From language as a resource to sources of meaning in multilingual mathematics classrooms. Journal of Mathematical Behavior, 50,155-168. https://doi.org/10.1016/j.jmathb.2018.02.007

Bilmes, J. (1988). The concept of preference in conversation analysis. Language in Society, 17(2), 161-181.

Byun, S. (2019). Against the epistemic horizon toward powerful discourse. In Otten, S., Candela, A. G., de Araujo, Z., Haines, C., \& Munter, C. (2019). Proceedings of the fortyfirst annual meeting of the North American Chapter of the International Group for the Psychology of Mathematics Education (pp. 1649-1658). St Louis, MO: University of Missouri.

Cazden, C. B. (2001). Classroom discourse: The language of teaching and learning (2nd ed.). Portsmouth, NH: Heinemann.

Cobb, P., Wood, T., Yackel, E., \& McNeal, B. (1992). Characteristics of classroom mathematics traditions: An interactional analysis. American Educational Research Journal, 29(3), 573604.

Daniels, H. (2016). Vygotsky and pedagogy (2nd ed.). London, UK: Routledge.

Drew, P. (1981). Adults' corrections of children's mistakes: A response to Wells and Montgomery. In P. French \& M. MacLure (Eds.), Adult-child conversation (pp. 244-267). London, UK: Croom Helm.

Drew, P. (2013). Turn design. In J. Sidnell \& T. Stivers (Eds.), The handbook of conversation analysis (pp. 131-149). Chichester, UK: Blackwell Publishers Ltd.

Edwards, D., \& Mercer, N. (1987). Common knowledge: The development of understanding in the classroom. Abingdon, UK: Routledge.

Emanuelsson, J., \& Sahlström, F. (2008). The price of participation: Teacher control versus student participation in classroom interaction. Scandinavian Journal of Educational Research, 52(2), 205-223. https://doi.org/10.1080/00313830801915853

Forman, E. A., Larreamendy-Joerns, J., Stein, M. K., \& Brown, C. A. (1998). “You're going to want to find out which and prove it": Collective argumentation in a mathematics 
classroom. Learning and Instruction, 8(6), 527-548. https://doi.org/10.1016/S09594752(98)00033-4

Goizueta, M. (2019). Epistemic issues in classroom mathematical activity: There is more to students' conversations than meets the teacher's ear. Journal of Mathematical Behavior. https://doi.org/10.1016/j.jmathb.2019.01.007

Heinemann, T., Lindström, A., \& Steensig, J. (2011). Addressing epistemic incongruence in question-answer sequences through the use of epistemic adverbs. In T. Stivers, L. Mondada, \& J. Steensig (Eds.), The morality of knowledge in conversation (pp. 107-130). Cambridge, UK: Cambridge University Press. https://doi.org/10.1017/CBO9780511921674.006

Hellermann, J. (2003). The interactive work of prosody in the IRF exchange: Teacher repetition in feedback moves. Language in Society, 32(1), 79-104. https://doi.org/10.1017/S0047404503321049

Herbst, P., \& Kosko, K. W. (2013). Using representations of practice to elicit mathematics teachers' tacit knowledge of practice: A comparison of responses to animations and videos. Journal of Mathematics Teacher Education, 17(6), 515-537. https://doi.org/10.1007/s10857-013-9267-y

Heritage, J. (1984a). A change-of-state token and aspects of its sequential placement. In J. M. Atkinson \& M. Heritage (Eds.), Structures of social action: Studies in conversation analysis (pp. 299-345). Cambridge: Cambridge University Press.

Heritage, J. (1984b). Garfinkel and Ethnomethodology. New York, NY: Polity Press.

Heritage, J. (2009). Questioning in medicine. In A. Freed \& S. Ehrlich (Eds.), Why Do You Ask?: The Function of Questions in Institutional Discourse. Oxford, UK: Oxford University Press. https://doi.org/10.1093/acprof:oso/9780195306897.001.0001

Heritage, J. (2012a). Epistemics in action: Action formation and territories of knowledge. Research on Language and Social Interaction, 45(1), 1-29. https://doi.org/10.1080/08351813.2012.646684

Heritage, J. (2012b). The epistemic engine: Sequence organization and territories of knowledge. Research on Language and Social Interaction, 45(1), 30-52. https://doi.org/10.1080/08351813.2012.646685

Heritage, J., \& Raymond, G. (2005). The terms of agreement: Indexing epistemic authority and subordination in talk-in-interaction. Social Psychology Quarterly, 68(1), 15-38. https://doi.org/10.1177/019027250506800103

Heritage, J., \& Raymond, G. (2012). Navigating epistemic landscapes: Acquiescence, agency and resistance in responses to polar questions. In J. P. de Ruiter (Ed.), Questions: Formal, functional and interactional perspectives (pp. 179-192). Cambridge: Cambridge University Press.

Hofmann, R., \& Ruthven, K. (2018). Operational , interpersonal , discussional and ideational dimensions of classroom norms for dialogic practice in school mathematics. British Educational Research Journal, 44(3), 496-514. https://doi.org/10.1002/berj.3444

Hogan, D., Rahim, R. A., Chan, M., Kwek, D., \& Towndrow, P. (2012). Understanding classroom talk in secondary three mathematics classes in Singapore. In B. Kaur \& T. L. Toh (Eds.), Reasoning, Communication and Connections in Mathematics: Yearbook 2012, Association of Mathematics Educators (pp. 169-197). https://doi.org/10.1142/9789814405430_0009 
Ingram, J. (2012). Whole class interaction in the mathematics classroom: A conversation analytic approach. (Unpublished PhD thesis). University of Warwick, UK.

Ingram, J. (2018). Moving forward with ethnomethodological approaches to analysing mathematics classroom interactions. ZDM - Mathematics Education, 50(6), 1065-1075. https://doi.org/10.1007/s11858-018-0951-3

Ingram, J., \& Andrews, N. (2019). Claims and demonstrations of understanding in whole class interactions. In Jankvist, U. T., Van den Heuvel-Panhuizen, M., \& Veldhuis, M. (Eds.). (2019). Proceedings of the Eleventh Congress of the European Society for Research in Mathematics Education (CERME11, February 6 - 10, 2019). Utrecht, the Netherlands: Freudenthal Group \& Freudenthal Institute, Utrecht University and ERME.

Ingram, J., Andrews, N., \& Pitt, A. (2017). Revisiting the roles of interactional patterns in mathematics classroom interaction. In T. Dooley \& G. Gueudet (Eds.), Proceedings of the 10th Congress of Research in Mathematics Education, (pp. 1300-1307). Dublin, Ireland: Dublin: DCU and ERME.

Ingram, J., Andrews, N., \& Pitt, A. (2019). When students offer explanations without the teacher explicitly asking them to. Educational Studies in Mathematics, 101(1), 51-66. https://doi.org/10.1007/s10649-018-9873-9

Ingram, J., \& Elliott, V. (2019). Research methods for classroom discourse. London, UK: Bloomsbury.

Ingram, J., Pitt, A., \& Baldry, F. (2015). Handling errors as they arise in whole-class interactions. Research in Mathematics Education, 17(3), 183-197. https://doi.org/10.1080/14794802.2015.1098562

Jakonen, T. (2014). Knowing matters: How Students Address Lack of Knowledge in Bilingual Classroom Interaction. (Unpublished PhD Thesis). University of Jyväskylä, Finland.

Jefferson, G. (2004). Glossary of transcript symbols with an introduction. In G. H. Lerner (Ed.), Conversation analysis: Studies from the first generation (pp. 13-31). Amsterdam/Philadelphia: John Benjamins Publishing Company.

Ju, M. K., \& Kwon, O. N. (2007). Ways of talking and ways of positioning: Students' beliefs in an inquiry-oriented differential equations class. Journal of Mathematical Behavior, 26(3), 267-280. https://doi.org/10.1016/j.jmathb.2007.10.002

Kämäräinen, A., Björn, P., Eronen, L., \& Kärnä, E. (2019). Managing epistemic imbalances in peer interaction during mathematics lessons. Discourse Studies, 21(3), 280-299. https://doi.org/10.1177/1461445619829236

Keevallik, L. (2011). The terms of not knowing. In T. Stivers, L. Mondada, \& J. Steensig (Eds.), The morality of knowledge in conversation (pp. 184-206). Cambridge, UK: Cambridge University Press. https://doi.org/10.1017/СВ09780511921674.009

Koole, T. (2010). Displays of epistemic access: Student responses to teacher explanations. Research on Language and Social Interaction, 43(2), 183-209. https://doi.org/10.1080/08351811003737846

Koole, T. (2012a). Teacher evaluations: Assessing "knowing", "understanding", and "doing." In G. Rasmussen, C. E. Brouwer, \& D. Day (Eds.), Evaluating Cognitive Competences in Interaction. (pp. 43-66). Philadelphia, PA: John Benjamins Publishing Company.

Koole, T. (2012b). The epistemics of student problems: Explaining mathematics in a multi- 
lingual class. Journal of Pragmatics, 44(13), 1902-1916.

https://doi.org/10.1016/j.pragma.2012.08.006

Krummheuer, G. (2015). Methods for reconstructing processes of argumentation and participation in primary mathematics classroom interaction. In A. Bikner-Ahsbahs, C. Knipping, \& N. Presmeg (Eds.), Approaches to qualitative research in mathematics education: Examples of methodology and methods (pp. 51-74). Cham, Switzerland: Springer. https://doi.org/10.1007/978-94-017-9181-6

Lee, Y.-A. (2007). Third turn position in teacher talk: Contingency and the work of teaching. Journal of Pragmatics, 39(6), 1204-1230. https://doi.org/10.1016/j.pragma.2006.11.003

Lefstein, A., \& Snell, J. (2011). Classroom discourse: The promise and complexity of dialogic practice. In S. Ellis \& E. McCartney (Eds.), Applied Linguistics and Primary School Teaching (pp. 165-185). Cambridge, UK; Cambridge University Press. https://doi.org/10.1017/СB09780511921605.018

Levenson, E., Tirosh, D., \& Tsamir, P. (2009). Students' perceived sociomathematical norms: The missing paradigm. Journal of Mathematical Behavior, 28(2-3), 171-187. https://doi.org/10.1016/j.jmathb.2009.09.001

Lindwall, O., \& Lymer, G. (2011). Uses of "understand" in science education. Journal of Pragmatics, 43(2), 452-474. https://doi.org/10.1016/j.pragma.2010.08.021

Macbeth, D. (2004). The relevance of repair for classroom correction. Language in Society, 33(5), 703-736. https://doi.org/10.1017/S0047404504045038

Margutti, P., \& Drew, P. (2014). Positive evaluation of student answers in classroom instruction. Language and Education, 28(5), 436-458. https://doi.org/10.1080/09500782.2014.898650

Mason, J., \& Spence, M. (1999). Beyond mere knowledge of mathematics: The importance of knowing-to act in the moment. Educational Studies in Mathematics, 38(1), 135-161. https://doi.org/10.1023/A:1003622804002

Mehan, H. (1979a). Learning lessons: Social organization in the classroom. Cambridge, Mass: Harvard University Press.

Mehan, H. (1979b). "What time is it, Denise": asking known information question in classroom discourse. Theory into Practice, 18(4), 285-294.

Mehan, H., \& Wood, H. (1975). The morality of ethnomethodology. Theory and Society, 2(1), 509-530.

Moschkovich, J. N. (2015). Academic literacy in mathematics for English Learners. Journal of Mathematical Behavior, 40, 43-62. https://doi.org/10.1016/j.jmathb.2015.01.005

Pirie, S., \& Kieren, T. (1994). Growth in mathematical undertsanding: How can we characterize it and how can we represent it? Educational Studies in Mathematics, 26, 165-190.

Planas, N., \& Gorgorió, N. (2004). Are different students expected to learn norms differently in the mathematics classroom? Mathematics Education Research Journal, 16(1), 19-40. https://doi.org/10.1007/BF03217389

Psathas, G. (1995). Conversation analysis. London, UK: Sage.

Raymond, G., \& Heritage, J. (2006). The epistemics of social relations: Owning grandchildren. Language in Society, 35(November), 677-705. 
https://doi.org/10.1017/S0047404506060325

Reis, G., \& Barwell, R. (2012). The interactional accomplishment of not knowing in elementary school science and mathematics: Implications for classroom performance assessment practices. International Journal of Science and Mathematics Education, 11(5), 1067-1085. https://doi.org/10.1007/s10763-012-9377-5

Rønning, F., \& Strømskag, H. (2017). Entering the mathematical register through evolution of the material milieu for classification of polygons. In T. Dooley \& G. Gueudet (Eds.), Proceedings of the 10th Congress of Research in Mathematics Education (pp. 13481355). Dublin: DCU and ERME.

Roth, W., \& Gardner, R. (2012). "They're gonna explain to us what makes a cube a cube?" Geometrical properties as contingent achievement of sequentially ordered childcentered mathematics lessons. Mathematics Education Research Journal, 24, 323-346.

Rowland, T. I. M. (1995). Hedges in mathematics talk: Linguistic pointers to uncertainty. Educational Studies in Mathematics, 29, 327-353.

Ryan, U., \& Parra, A. (2019). Epistemological aspects of multilingualism in mathematics education: an inferentialist approach. Research in Mathematics Education, 21(2), 152167. https://doi.org/10.1080/14794802.2019.1608290

Sacks, H. (1992). Lectures on conversation (G. Jefferson, Ed.). Oxford: Blackwell.

Schegloff, E. A. (2007). Sequence organization in interaction: A primer in conversation analysis. Cambridge, UK: Cambridge University Press.

Sekiguchi, Y. (2006). Mathematical norms in Japanese mathematics lessons. In D. Clarke, C. Keitel, \& Y. Shimizu (Eds.), Mathematics classrooms in twelve countries: The insider's perspective (pp. 289-306). Rotterdam, The Netherlands: Sense Publishers.

Sert, O., \& Walsh, S. (2013). The interactional management of claims of insufficient knowledge in English language classrooms. Language and Education, 27(6), 542-565. https://doi.org/10.1080/09500782.2012.739174

Sidnell, J. (2010). Conversation analysis: An introduction. Chichester, UK: Wiley-Blackwell.

Sidnell, J., \& Stivers, T. (2012). The handbook of conversation analysis. Oxford, UK: WileyBlackwell.

Sierpinska, A. (1994). Understanding in Mathematics. London, UK: The Falmer Press.

Solem, M. S. (2016). Displaying knowledge through interrogatives in student-initiated sequences. Classroom Discourse, 7(1), 18-35. https://doi.org/10.1080/19463014.2015.1095105

Staats, S., \& Batteen, C. (2010). Linguistic indexicality in algebra discussions. Journal of Mathematical Behavior, 29(1), 41-56. https://doi.org/10.1016/j.jmathb.2010.01.002

Stivers, T. (2008). Stance, alignment, and affiliation during storytelling: When nodding is a token of affiliation. Research on Language and Social Interaction, 41(1), 31-57. https://doi.org/10.1080/08351810701691123

Stivers, T. (2011). Morality and question design. In T. Stivers, L. Mondada, \& J. Steensig (Eds.), The morality of knowledge in conversation (pp. 82-106). Cambridge, UK: Cambridge University Press. 
Stivers, T., Mondada, L., \& Steensig, J. (2011). Knowledge, morality and affiliation in social interaction. In T. Stivers, L. Mondada, \& J. Steensig (Eds.), The morality of knowledge in conversation. Cambridge, UK: Cambridge University Press. https://doi.org/10.1017/CBO9780511921674.002

Stivers, T., \& Robinson, J. D. (2006). A preference for progressivity in interaction. Language in Society, 35(3), 367-392. https://doi.org/10.1017/S0047404506060179

Stivers, T., \& Rossano, F. (2010). Mobilizing response. Research on Language and Social Interaction, 43(1), 3-31. https://doi.org/10.1080/08351810903471258

Tainio, L., \& Laine, A. (2015). Emotion work and affective stance in the mathematics classroom: the case of IRE sequences in Finnish classroom interaction. Educational Studies in Mathematics, 89(1), 67-87. https://doi.org/10.1007/s10649-015-9591-5

Vogler, A., Prediger, S., Quasthoff, U., \& Heller, V. (2018). Students ' and teachers ' focus of attention in classroom interaction - subtle sources for the reproduction of social disparities. Mathematics Education Research Journal, 30, 299-323.

Vygotsky, L. S. (1978). Mind in society: The development of higher psychological processes. Cambridge, MA: Harvard University Press.

Wells, G. (1993). Reevaluating the IRF sequence: A proposal for the articulation of theories of activity and discourse for the analysis of teaching and learning in the classroom. Linguistics and Education, 5(1), 1-37. https://doi.org/10.1016/S0898-5898(05)80001-4

Wilkinson, L. C. (2018). Teaching the language of mathematics: What the research tells us teachers need to know and do. Journal of Mathematical Behavior, 51, 167-174. https://doi.org/10.1016/j.jmathb.2018.05.001

Wood, T., Cobb, P., \& Yackel, E. (1993). Chapter 6 : The nature of whole-class discussion. Journal for Research in Mathematics Education, 6, 55-68.

Xu, L., \& Clarke, D. (2013). Meta-rules of discursive practice in mathematics classrooms from Seoul, Shanghai and Tokyo. ZDM - International Journal on Mathematics Education, 45(1), 61-72. https://doi.org/10.1007/s11858-012-0442-x

Yackel, E., \& Cobb, P. (1996). Sociomathematical norms, argumentation, and autonomy in mathematics. Journal for Research in Mathematics Education, 27(4), 458-477.

Yackel, E., \& Rasmussen, C. (2002). Beliefs and norms in the mathematics classroom. In G. C. Leder, E. Pehkonen, \& G. Törner (Eds.), Beliefs: A hidden variable in mathematics education? (pp. 313-344). https://doi.org/10.1007/0-306-47958-3_18 